\title{
Reformas educacionais de hoje As implicações para a democracia
}

\author{
Vera Peroni* \\ Maria Raquel Caetano* \\ PAUla DE Lima**
}

\begin{abstract}
RESUMO: Este artigo destaca as relações entre o público e o privado na educação através da análise dos sujeitos vinculados ao setor privado mercantil e a tendências neoconservadoras que influenciam a política educacional e o conteúdo das propostas. Eles atuam na elaboração da Base Nacional Comum Curricular (BNCC), na Reforma do Ensino Médio e no programa Escola sem Partido (ESP), promovendo a censura nos sistemas e nas escolas através de um conteúdo para a educação que traz graves implicações para a democracia.
\end{abstract}

Palavras-chave: Público-privado. Sujeitos individuais e coletivos. Democratização. Privatização; Neoconservadorismo.

\section{Today's educational reforms \\ The implications for democracy}

\begin{abstract}
This article highlights the relations between the public and the private sectors in education through an analysis of the subjects related to the private commercial sector and neoconservative tendencies which influence educational policy and the content of the proposals. They focus on the elaboration of the National Curricular Joint
\end{abstract}

* É doutora em Educação e professora da Universidade Federal do Rio Grande do Sul nos cursos de graduação e pós-graduação em Educação. É pesquisadora produtividade CNPQ. Coordena grupo de pesquisa sobre a relação entre o público e o privado na educação. Porto Alegre, RS- Brasil. E-mail:<veraperoni@gmail.com>.

** É Mestre em Educação pela Pontifícia Universidade Católica do Rio Grande do Sul e Doutora em Educação pela Universidade Federal do Rio Grande do Sul. Atualmente atua como professora no Instituto Federal de Educação, Ciência e Tecnologia- Campus Charqueadas. Charqueadas, RS- Brasil. E-mail:<caetanoraquel2013@gmail.com>.

*** Graduada em Pedagogia pela Universidade Federal do Rio Grande do Sul. É membro do Grupo de Pesquisa Relações entre o Público e o Privado na Educação (GPRPPE). Porto Alegre, RS-Brasil. E-mail:<paulavdelima@hotmail.com>. 
Base (BNCC), High School Reform and the School Without a Party (ESP) program, promoting censorship in systems and schools using content for education that has serious implications for democracy.

Keywords: Public-private. Individual and collective subjects. Democratization. Privatization. Neoconservatism.

\section{Reformas educativas de hoy}

Las implicaciones en la democracia

RESUMEN: Este artículo destaca las relaciones entre lo público y lo privado en la educación mediante el análisis de los sujetos vinculados con el sector privado mercantil y tendencias neoconservadoras que influyen en la política educativa y el contenido de las propuestas. Ellos actúan en la elaboración de la Base Nacional Común Curricular (BNCC), en la Reforma de la Enseñanza Secundaria y en el programa Escuela sin Partido (ESP), promoviendo la censura en los sistemas y en las escuelas por medio de un contenido para la educación que tiene graves implicaciones en la democracia.

Palabras clave: Público-privado. Sujetosindividuales y colectivos. Democratización. Privatización. Neoconservadurismo.

\section{Les reformes éducatives d'aujourd'hui:}

Les implications pour la démocratie

RÉSUMÉ: Cet article met en évidence les relations entre le public et le privé dans l'éducation à travers l'analyse de sujets liés au secteur privé du commerce et les tendances néoconservatrices qui influencent la politique éducative et le contenu de ses propositions. On note leur participation dans l'élaboration de la Base Nationale Commune du Programme Scolaire, dans la Réforme de l'Enseignement Secondaire tout comme dans le programme Ecole sans Parti, par la promotion de la censure dans les systèmes et les écoles via un contenu éducationnel qui a de sérieuses implications pour la démocratie.

Mots-clés: Public-Privé. Sujets indivivuels et collectifs. Democratisation. Privatisation; Néoconservatisme. 


\section{Introdução}

E

ste artigo traz elementos para o debate sobre as redefinições no papel do Estado que reestabelecem as fronteiras entre o público e o privado. $\mathrm{O}$ texto é baseado em pesquisas, que analisam os processos de materialização do privado no público nas etapas e modalidades da educação básica no Brasil. A pesquisa atual analisa os sujeitos e o conteúdo da proposta, destacando que o privado não é uma abstração e não há apenas uma linha de atuação no privado quanto ao seu conteúdo, ou seja, há uma multiplicidade de sujeitos e conteúdos tentando dar a direção para a educação pública.

Priorizaremos a análise dos sujeitos que estão atuando na direção da política educacional, vinculados ao mercado e ao neoconservadorismo, que atuam na elaboração da Base Nacional Comum Curricular (BNCC), na Reforma do Ensino Médio e no Escola Sem Partido (ESP), ressaltando as implicações para a democratização da educação. Democracia não é aqui entendida como uma abstração, mas como a materialização de direitos em políticas coletivamente construídas na autocrítica da prática social (PERONI, 2015).

A mercadificação da educação pública também não é uma abstração; ela ocorre via sujeitos e processos. Sujeitos individuais e coletivos (THOMPSON, 1981) que estão cada vez mais organizados, em redes do local ao global, com diferentes graus de influência e que falam de diferentes lugares: setor financeiro, organismos internacionais, setor governamental. Algumas instituições têm fins lucrativos e outras não (ou não claramente), mas as redes são sujeitos (individuais e coletivos) em relação, com projeto de classe (PERONI, 2016).

As fronteiras entre o público e o privado têm se modificado neste período de crise do capitalismo, em que as suas estratégias de superação - neoliberalismo, globalização, reestruturação produtiva e Terceira Via - redefinem o papel do Estado, principalmente para com as políticas sociais (PERONI, 2006).

A política educacional não é, simplesmente, determinada pelas mudanças sociais e econômicas, mas é parte constitutiva dessas mudanças (PERONI, 2003). Neste sentido, o Estado, assim como o capital, deve ser visto como relação ou processo (HARVEY, 2008), como parte importante de um movimento de correlação de forças de sujeitos (THOMPSON, 1981). Em nossos estudos dos processos de privatização do público, é assim que analisamos os projetos societários de classe em disputa, e não de uma contraposição entre Estado e sociedade civil. Até porque vivemos ainda em uma sociedade hegemonizada pelo capital em que sociedade civil e Estado são perpassados por interesses mercantis (PERONI, 2016). Premidos pelo movimento do real na sociedade brasileira, iniciamos também a análise dos sujeitos vinculados ao neoconservadorismo, pelo seu protagonismo neste momento, trazendo como exemplo o movimento Escola Sem Partido (ESP).

No Brasil, mais de $80 \%$ das matrículas do ensino fundamental e médio estão na rede pública. A expansão da educação básica é uma realidade no país, principalmente 
após o Fundeb e a Emenda Constitucional que ampliou a obrigatoriedade da educação de 4 a 17 anos. Estão em disputa projetos societários e de educação que se traduzem no conteúdo da educação, entendido como currículo, gestão, formação de professores, organização do sistema e escola; enfim, a alma da educação.

A educação, como parte de um projeto de nação, é disputada por visões antagônicas, tanto no sentido da sua direção, quanto na execução. Diferentes formas de privatização vêm ocorrendo a partir e/ou como consequência das reformas da gestão pública, instituindo reformas educativas de forma global. A disputa fica ainda mais clara quando examinamos os fatos a partir do golpe parlamentar de 2016, que retirou da Presidência da República, com o apoio do empresariado nacional, uma presidenta eleita pelo voto popular. Na concretização do golpe, a

radicalização do projeto liberal, derrotado nas últimas quatro eleições, caminha no sentido de levar ao extremo a reforma do Estado iniciada nos anos de 1990. O objetivo é "privatizar tudo o que for possível", tanto na infraestrutura econômica quanto na infraestrutura social (FAGNANI, 2017, p.11).

Sob o projeto pós-golpe no Brasil, as reformas educacionais não são debatidas com associações de professores, sindicatos, pesquisadores, e estão sendo aprovadas sob sua resistência, como no caso da Reforma do Ensino Médio, da Base Nacional Comum Curricular (BNCC) e do ESP, que vêm demonstrando a disputa por projetos distintos e que tem como foco a direção e o conteúdo da educação pública brasileira.

Diferentes processos de privatização da educação pública em nível de sistema e escola trazem implicações para a democratização da educação, identificando os sujeitos que vêm atuando para dar a direção das políticas educacionais neste momento histórico, político e social.

O mercado na direção das políticas educativas

As reformas na educação brasileira fazem parte de um projeto que não dialoga com os principais envolvidos nas propostas em curso - professores, alunos, comunidade escolar - e apresenta-se como uma afronta à democracia. Os principais envolvidos no processo de construção de uma base nacional comum curricular e do novo ensino médio se apresentam como sujeitos individuais ou coletivos através de instituições públicas e privadas que atuam no setor educacional, institutos e fundações ligados a grandes empresas nacionais e internacionais, bem como instituições financeiras ligadas ao mercado de capitais, visando construir um projeto hegemônico de educação e de sociedade. Apresentamos na figura 1, os sujeitos das reformas em curso no Brasil. 
Figura 1 - Sujeitos individuais e coletivos das reformas em curso no Brasil.

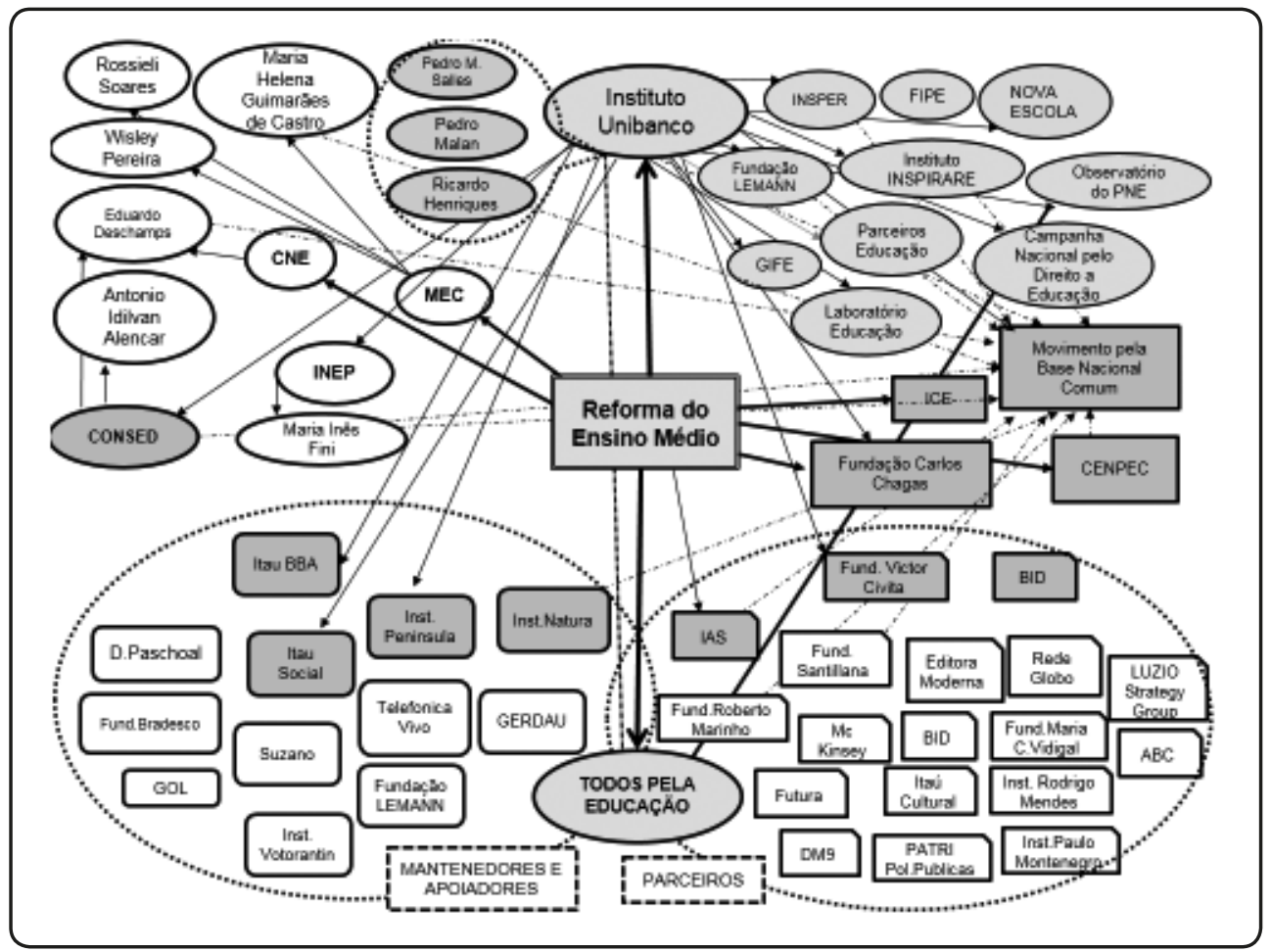

Fonte: Elaborado por CAETANO, 2017.

Para analisar a figura, é necessário identificar os sujeitos, entender como se relacionam e apresentar como são utilizadas as influências políticas na rede. É importante compreender como ocorrem os processos de troca de informação e recursos bem como os mecanismos que orientam essas trocas: regras, relações, ligações organizacionais etc.

A reforma do ensino médio tem como um dos principais sujeitos o Instituto Unibanco (IU), como aparece no alto e centro da figura. Fazem parte do Conselho de Governança: Pedro Moreira Salles, Pedro Malan e Ricardo Henriques (elencamos aqui os principais). Pedro Moreira Salles ${ }^{1}$ atualmente é presidente do Conselho de Administração do Itaú Unibanco, pertence a uma das quinze famílias mais ricas do Brasil. Ricardo Henriques é economista, atuou no Ministério da Educação e nos governos municipal e estadual do Rio de Janeiro. Atualmente, é superintendente executivo do IU. Pedro Malan ${ }^{2}$ foi ministro da fazenda nas duas gestões de FHC e atualmente é vice-presidente do IU.

O IU, por sua vez, opera com uma série de instituições através de parcerias públicoprivadas para viabilizar a implantação do programa Jovem de Futuro nas redes públicas de ensino médio. Essa é sua principal estratégia, além de construir direcionamento público em seminários, congressos, palestras, trazendo experiências internacionais. 
Atuando em várias frentes e em conjunto com seus parceiros, o IU divide a parceria em várias áreas de atuação. Na figura 1 essas instituições aparecem nas elipses e nos retângulos, nas quais as setas deslocam-se do IU em direção a essas instituições. Para cada área de atuação do IU, há um conjunto de parceiros:

a. Produção de conhecimento - coordenada pelo Núcleo de Pesquisa Aplicada em Economia da Educação: Fipe e Insper.

b. Financiamento: a agenda de financiamento às pesquisas executadas por outras instituições e pesquisadores externos, para investigar temas relacionados à gestão educacional, Ensino médio e juventudes é realizada com os parceiros: Itaú BBA, Fundação Itaú Social, Instituto Península, Fundação Carlos Chagas, Fundação Victor Civita.

c. Debate público: visa estimular o debate sobre os principais desafios contemporâneos educacionais, a fim de encontrar soluções e apontar caminhos para a melhoria da educação pública, com os parceiros: Folha de São Paulo, Fundação Getúlio Vargas e Insper.

d. Fortalecimento institucional, para fortalecer a rede de organizações da sociedade civil e atores relevantes no campo da educação: Consed, Campanha pelo Direito a Educação, Gife, Parceiros da Educação, Laboratório da Educação, Movimento pela Base, Todos pela Educação.

e. Qualidade do ensino médio, para o desenvolvimento, a implementação e a avaliação de instrumentos, recursos pedagógicos e de gestão, formação e tecnologias para a melhoria da qualidade do Ensino Médio: Fundação Lemann, Nova Escola, Inspirare, Inep, Observatório do PNE (Todos pela Educação).

f. Fomento, para viabilizar práticas com potencial de replicabilidade, atuando com fundos independentes de direitos e justiça social e instituições de pesquisa, por meio de um arranjo institucional de coautoria e colaboração, para identificar, monitorar, avaliar iniciativas e produzir conhecimento: Fundação Carlos Chagas, Baobá, Elas, UFScar.

g. Ação com juventudes, com o objetivo de contribuir para que os jovens adquiram novas perspectivas, desenvolvam seu potencial e possam transformar a realidade em que vivem, criaram conexões com outras instituições para realizar ações com as juventudes: Enem no Futura (Rede Globo), CBN (Rede Globo). (UNIBANCO, 2017).

Ressalta-se, na figura, as ligações que levam a Fundação Lemann ${ }^{3}$, principal articuladora da BNCC, e ao Movimento pela Base Nacional Comum Curricular. A Fundação Lemann possui uma página nas redes sociais de apoio ao Movimento pela Base. O Movimento Todos pela Educação também aparece como parceiro em diversos eventos com a Fundação Lemann, Consed e Undime, que se tornam, em diferentes momentos, porta de entrada para que essas instituições atuem com seu projeto hegemônico de sociedade e de educação (PERONI; CAETANO, 2015).

As instituições ligadas com as setas pontilhadas são as mesmas que atuam na reforma do ensino médio e no movimento pela BNCC, assim como a participação no Todos pela Educação, que reúne empresas que somam quase $80 \%$ do PIB nacional, fazem parte das quinze famílias mais ricas do Brasil, e têm como objetivo claro pesar decisivamente na correlação de forças em nossa sociedade. 
Participam ainda sujeitos individuais e coletivos que ocupam posições estratégicas no Ministério da Educação, como Maria Helena Guimarães de Castro, ${ }^{4}$ secretária executiva do MEC. Foi secretária de Educação de SP entre 2007 e 2009. Uma de suas bandeiras é a implementação de políticas meritocráticas ou de responsabilização na educação, isto é, pagamento de bonificação para escolas e professores de acordo com o cumprimento de metas de desempenho dos alunos, cujo conteúdo está alinhado aos projetos dos grupos privados. Maria Inês Fini, ${ }^{5}$ presidente do Instituto Nacional de Estudos e Pesquisas Educacionais (Inep), órgão responsável pela elaboração do Enem. Ambos os nomes compõem o quadro do PSDB. Wesley Pereira e Rossiele Castro estão ligados ao Instituto Unibanco e ao Movimento pela Base, assim como Eduardo Deschamps, ex-presidente do Consed e hoje presidente do CNE que teve atuação decisiva na direção da política. Conforme Gonçalves (2017), o Consed elaborou uma Carta de Princípios propondo ao MEC a flexibilização do currículo do EM, utilizando-se de dois estudos com instituições privadas, que analisaram o currículo do EM. No lançamento da Medida Provisória №. 746, o presidente do Consed na época, Eduardo Deschamps, defendeu a proposta junto ao MEC em entrevista coletiva. Logo depois, Deschamps foi indicado para o Conselho Nacional de Educação, assumindo a Presidência. O CNE será responsável por discutir e aprovar a BNCC. Há fortes relações entre esses sujeitos, individuais e coletivos, entre Estado e mercado.

O IU realizou em junho de 2017 em São Paulo, o "Seminário Internacional Desafios Curriculares do Ensino Médio: flexibilização e implementação", com o objetivo de

\begin{abstract}
contribuir para o fortalecimento do debate que ajude a pensar as mudanças da última etapa da educação básica na forma de propostas concretas de desenho e implementação de novos currículos. Busca dar um passo adicional na reflexão sobre a proposta de reestruturação do Ensino Médio do ponto de vista das exigências colocadas para as redes estaduais. Além da necessidade de alterar a formação inicial e continuada de professores, a flexibilização curricular exigirá a formulação de soluções definitivas e eficientes para velhos problemas estruturais, que poderão impedi-la de sair do papel (Disponível em http://www.seminariocurriculo.org.br/ site/2017/\#inicio. Acesso em 2 set. 2017).
\end{abstract}

No seminário, conforme as apresentações de gestores e articuladores, o desenho do novo ensino médio foi apresentado não como proposta, mas como política já consolidada. As apresentações emblemáticas ficaram por conta dos secretários estaduais de educação de Santa Catarina e Espírito Santo, em que mostraram uma série de parcerias com instituições para atender a nova política. No caso de Santa Catarina, o secretário de educação do estado, que também foi presidente do Consed e atualmente presidente do CNE, expôs as parcerias com Instituto Ayrton Senna, Instituto Natura e Itaú BBA, além do BID e Senai. Já o secretário de educação do Espirito Santo, exibiu as parcerias com o Instituto Ayrton Senna, Unibanco, ICE e Fundação Carlos Chagas. Esse caso é emblemático, pois as parcerias interferem no conteúdo da educação pública, na elaboração do currículo, na formação dos professores, na gestão escolar e no comportamento dos alunos. 
A Figura 1 mostra que os sujeitos privados influenciam fortemente na direção e na definição da política educacional brasileira, sem a participação ampla da população nas discussões. Quando políticas no nível nacional são gestadas retirando a participação, diálogo e autonomia da comunidade educacional, introduzidas de forma arbitrária, como é o caso da MP do ensino médio, e sem levar em consideração as construções já realizadas sobre os temas, temos a clara dimensão de qual projeto o capital quer para o país. Ademais, esses sujeitos encontram apoio naqueles que acreditam que suas ideias irão funcionar, ter impacto e gerar retorno como resultado social ou lucro (BALL, 2014).

A luta pela democratização da educação nas últimas décadas foi pela ampliação do espaço público e efetivação dos direitos, concretizados através das políticas educacionais. Problematizando essa questão, cabe ressaltar a importância dos mecanismos de gestão democrática assegurados pela legislação educacional brasileira.

Com a naturalização do privado no público, a democratização da educação e da escola retrocedem, há um esvaziamento da participação, autonomia e transparência dos sistemas e as políticas de educação são impressas de cima para baixo, de fora para dentro. É um conjunto de ideias gestadas por representantes do setor privado que vêm produzindo "políticas para e no interior do Estado" (BALL, 2014, p.162), especialmente para a educação pública. Pelo exposto até o momento, podemos dizer a partir de Ball (idem) que "soluções políticas estão à venda", tornando-se uma mercadoria.

Concordamos com Mészaros (2006) que "talvez nada exemplifique melhor o universo instaurado pelo neoliberalismo, em que 'tudo se vende, tudo se compra', 'tudo tem preço', do que a mercantilização da educação" (MÉSZAROS, 2006, p. 16, grifos do autor).

Além do processo de mercantilização da educação também abordaremos outros sujeitos, que têm atuado na direção das políticas, vinculados a propostas neoconservadoras e que promovem a censura no ambiente escolar. Destacamos o caso do Escola sem Partido, que apresentaremos na próxima seção.

\section{O neoconservadorismo e a Escola sem Partido}

O movimento Escola sem Partido (ESP) tem-se mostrado um sujeito coletivo atuante nas negociações políticas sobre a elaboração da Base Nacional Curricular Comum (BNCC) representado por parlamentares apoiadores e outros entusiastas, que participam ativamente do debate público acerca do documento, especialmente a partir da divulgação de sua segunda versão, em 2016. Sabe-se que a BNCC, por tratar essencialmente do currículo da educação, se consolidou como espaço de disputa por projetos educativos distintos (PERON; CAETANO, 2015). O ESP, a partir disso, atua deslocando a discussão acerca do que deve fazer parte do currículo definido pelo documento, para o que deve ser excluído dele, referindo-se "a demandas político-partidárias, raciais, de gênero e de 
sexualidade" (MACEDO, 2017, p. 517), incorporando, assim, os elementos principais da sua pauta: o combate às chamadas "doutrinação ideológica" e "ideologia de gênero".

O ESP, que surgiu em 2004 e teve um crescimento espantoso nos últimos cinco anos, atua por diferentes frentes, e suas consequências para a educação pública são devastadoras: cerceamento da democracia nas instituições, silenciamento e criminalização de professores, apagamento da diversidade, esvaziamento do sentido social do espaço escolar, entre outros. O projeto educativo do ESP é construído por aqueles a quem interessa uma escola cujo papel seja a preservação acrítica da ordem social vigente, inclusive suas desigualdades (LIMA, 2017) - em especial no que diz respeito às questões raciais, de gênero e sexualidade.

A proposta do ESP tem como elemento fundamental a censura, constituindo- se como espaço de encontro entre as agendas neoliberal e neoconservadora. Busca interditar o discurso e o trabalho dos professores, da educação básica ao ensino superior, decidindo sobre quais conhecimentos e conteúdos podem (ou não) permear o espaço escolar. No âmbito da censura - travestida de combate à doutrinação - os focos se dividem.

De um lado, os neoliberais pretendem eliminar da escola práticas que se propõem transgressoras, que questionam o pensamento hegemônico e procuram construir alternativas à lógica do capital. Seu objetivo final, nesse sentido,

é romper com a possibilidade de construção de uma educação vinculada às questões e valores sociais, políticos e culturais existentes na diversidade, e que possibilitam o exercício de uma prática democrática na escola [...], substituindo-a por uma educação sem espaço de participação, que promova a preservação acrítica do sistema capitalista e, consequentemente, das suas desigualdades (LIMA, 2017, p. 44).

De outro lado, os neoconservadores justificam a censura como uma forma de garantir a moralidade e a tradição e impedir que os professores subvertam aos valores morais tradicionais. É nesse sentido que surge o elemento do combate à "ideologia de gênero", que "passa a ser bandeira prioritária de grupos religiosos conservadores e funde-se à pauta do movimento ESP que transfere sua discussão do campo político, para o campo moral" (MIGUEL, 2016, apud, LIMA, 2017, p. 26-27).

Desse modo, é evidente que o ESP é construído por diferentes elementos e por sujeitos que têm, entre si, diferentes enfoques na atuação, mas é certo que em muitos momentos as duas questões se encontram e parecem fundir-se em um pensamento único. As pautas do movimento, mesmo as que se originam a partir de ideias neoliberais, assumem um caráter bastante neoconservador, especialmente no que diz respeito à regulamentação do trabalho dos professores, que se torna padronizado e policiado, não somente em relação ao conteúdo a ser apresentado, mas também em relação aos métodos (APPLE, 2003). Justamente, a ESP é “esse regime de controle (neoconservador) [que] não se baseia na confiança, mas numa suspeita profunda das motivações e da competência dos professores" (APPLE, 2003, p. 63). 
Harvey (2008) auxilia na compreensão da relação entre neoliberalismo e neoconservadorismo, expressando que

Em sua preocupação com a ordem, o neoconservadorismo se assemelha a uma mera retirada do véu de autoritarismo com que o neoliberalismo se cobre. Mas também propõe respostas singulares a uma das contradições centrais desse último. Se 'a sociedade não existe, apenas homens e mulheres individuais', como disse de início Thatcher, o caos individual pode vir a se sobrepor à ordem. A anarquia do mercado, da competição sem peias (esperanças, desejos, ansiedades e temores individuais; escolhas de estilo de vida de hábitos e orientações sexuais, formas de auto - expressão e comportamentos com relação aos outros) gera uma situação cada vez mais ingovernável (Harvey, 2008, p. 92-93).

O autor ressalta, ainda, que o aumento do desemprego, dos ajustes estruturais que minimizam as políticas sociais e a exacerbação da competitividade e individualismo pode provocar caos social e civilizatório e a este risco o neoconservadorismo responde com maior repressão. E com

Valores morais centrados no nacionalismo cultural, na retidão moral, no cristianismo (de uma certa moralidade evangélica) nos valores familiares e em questões de direito à vida, assim como no antagonismo a novos movimentos sociais como o feminismo, os direitos homossexuais, a ação afirmativa e o ambientalismo (Harvey, 2008, p. 94).

Estes valores, em maior ou menor grau, são o ponto de encontro dos diferentes sujeitos que atuam no sentido da formulação, divulgação e implementação das propostas do ESP, que aparecem na figura abaixo e serão apresentados em seguida. 
Figura 2 - Sujeitos do ESP

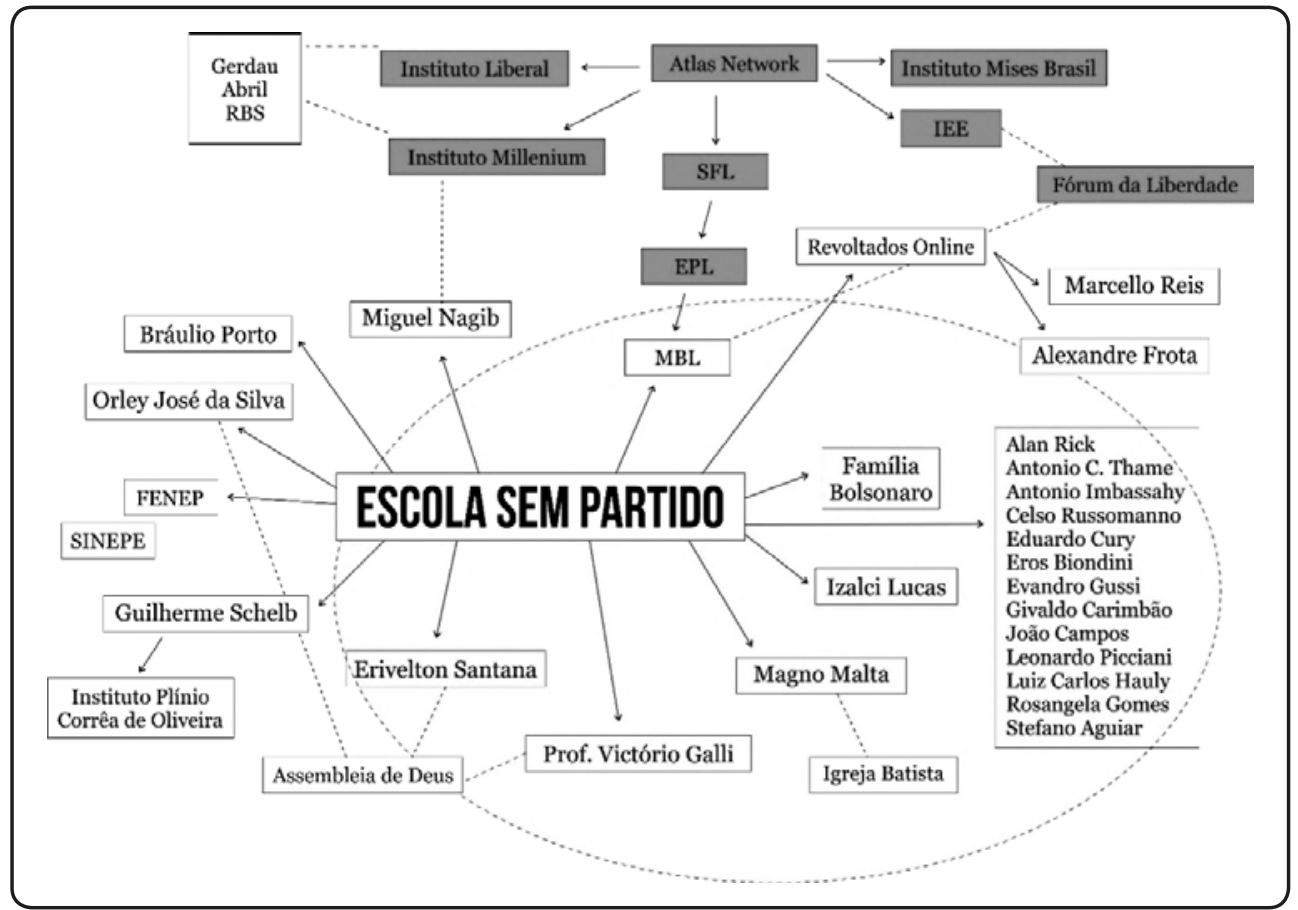

Fonte: Elaborado por LIMA, 2017.

Miguel Francisco Urbano Nagib é o fundador do movimento ESP e, portanto, figura central entre os demais sujeitos. É a principal figura pública do movimento, participando de programas, entrevistas e audiências públicas, com um repertório de argumentos prontos que são frequentemente repetidos nos diferentes espaços (MOURA, 2016). Advogado e procurador do estado de São Paulo, Nagib também é proprietário da Escola Sem Partido Treinamento e Aperfeiçoamento (Eireli - ME), cuja atividade principal está ligada ao treinamento em desenvolvimento profissional e gerencial, e da Associação Escola Sem Partido, responsável por atividades de associações de defesa de direitos sociais. Miguel Nagib foi articulista do Instituto Millenium (IMil), do qual trataremos mais tarde, tendo chegado a publicar, em 2009, um artigo intitulado "Por uma escola que promova os valores do Instituto Millenium". Depois que Nagib se desvinculou do IMil, a assinatura do texto foi modificada para "Comunicação Millenium" e hoje o texto já não está mais disponível no site do instituto, "certamente porque se percebeu a contradição entre o combate à 'doutrinação nas escolas' e a defesa de um programa pedagógico tão ostensivamente doutrinário" (MIGUEL, 2016).

Outros sujeitos individuais relevantes na rede do ESP são Bráulio Porto de Matos, professor da Faculdade de Educação da Universidade de Brasilia (UnB), e Orley José da Silva, também professor, estudioso da teologia e pesquisador informal do livro didático 
e currículo escolar. Ambos contribuem teoricamente com o movimento, discutindo a "doutrinação ideológica nas escolas", sendo o segundo voltado à questão dos livros didáticos. Bráulio é atualmente citado nos materiais do movimento como "colaborador" do ESP, mas já apareceu no site do movimento como seu "vice-presidente". Orley é criador do blog "De olho no livro didático", indicado na página eletrônica do movimento. Segundo Brait (2016), o professor é membro da Assembleia de Deus e milita no evangelismo universitário há quase 20 anos.

O autor analisa e reproduz páginas de vários materiais didáticos, fazendo crítica a conteúdos tidos como marxistas e aos livros que apagam valores fundamentais do cristianismo. Denuncia a presença de livros que podem doutrinar as crianças (BRAIT, 2016, p. 163).

A Federação Nacional das Escolas Particulares (Fenep) não apresenta posição oficial de apoio aos projetos de lei propostos pelo movimento, mas considera a pauta da doutrinação nas escolas muito relevante, por isso promoveu junto ao ESP o $1^{\stackrel{0}{ } \text { Congresso }}$ Nacional sobre Doutrinação Política e Ideológica nas Escolas, em 2014. Na ocasião, logo após a fala da presidente da Fenep, Amábile Pacios, Miguel Nagib reforçou que o congresso não era apenas sobre a doutrinação, mas contra ela e que todos os palestrantes do evento compartilham da crença de que há uma verdade para cada coisa e buscar essa verdade é não apenas possível, mas obrigatório. Da mesma forma, o Sindicato do Ensino Privado (Sinepe) não apresenta posicionamento oficial sobre o movimento, mas já organizou atividades em parceria com o ESP. Foi o caso de uma palestra com o tema "Ideologização nas escolas: o abuso da liberdade de ensinar", de Miguel Nagib, a convite do Sinepe/RS para o Seminário de Diretores, em maio de 2015, em Porto Alegre. Na ocasião, professores de escolas privadas se reuniram em assembleia geral para aprovar uma moção de repúdio ao Sinepe.

O procurador Guilherme Schelb e o Instituto Plínio Corrêa de Oliveira (IPCO) uma das organizações sucessoras da Sociedade Brasileira de defesa da Tradição, Família e Propriedade (TFP), que busca mobilizar a sociedade com vistas a preservar os pilares básicos da Civilização Cristã, que estariam "ameaçados pela Revolução anti-cristã" - são sujeitos que se tornaram importantes para a atuação do movimento, quando da criação do documento chamado "Modelo de notificação extrajudicial”, documento importante na atuação do movimento, que funciona como um instrumento provisório, enquanto o ESP não é incorporado à legislação (LIMA, 2017).

Os sujeitos que aparecem na elipse cinza são os vinculados à disputa que se trava no campo legislativo, são os autores dos seis projetos relacionados ao ESP que tramitam em nível federal também, cujos projetos apresentados são listados abaixo, segundo a ordem de proposição: 
» Proposto pelo deputado Erivelton Santana - PL 7180/2014: "Inclui entre os princípios do ensino o respeito às convicções do aluno, de seus pais ou responsáveis, dando precedência aos valores de ordem familiar sobre a educação escolar nos aspectos relacionados à educação moral, sexual e religiosa";

» Também de autoria de Erivelton Santana - PL 7181/2014: “Dispõe sobre a fixação de parâmetros curriculares nacionais em lei com vigência decenal";

» Proposto pelo deputado Izalci Lucas - PL 867/2015: “Inclui, entre as diretrizes e bases da educação nacional, o 'Programa Escola sem Partido"';

» Proposto por 16 deputados - PL 1859/2015: "Acrescenta Parágrafo único ao artigo $3^{0}$ da Lei 9.394/96 (Lei de Diretrizes e Bases da Educação)";

» Proposto pelo deputado Prof. Victório Galli - PL 5487/2016: “Institui a proibição de orientação e distribuição de livros às escolas públicas pelo Ministério da Educação e Cultura que verse sobre orientação de diversidade sexual para crianças e adolescentes";

» Proposto pelo senador Magno Malta - PLS 193/2016: "Inclui entre as diretrizes e bases da educação nacional, de que trata a Lei no 9.394, de 20 de dezembro de 1996, o 'Programa Escola sem Partido'".

O deputado Erivelton Santana (PEN, mas filiado ao PSC na ocasião da proposta) é pastor evangélico, ligado à igreja Assembleia de Deus e compõe a Frente Parlamentar Evangélica do Congresso Nacional, a Frente Parlamentar em Defesa da Vida e da Família, a Frente Parlamentar Mista da Família e Apoio à vida.

Professor Victório Galli (PSC) também é ligado à igreja Assembleia de Deus e é conhecido por se opor a diversos projetos que tratam da temática dos direitos das pessoas LGBT. O deputado se mostra contrário ao PL 122/2006, que criminaliza a homofobia, enquanto é proponente do PL 4879/2016, que qualifica os homicídios a líderes religiosos como crime hediondo. Também é proponente do PL 5487/2016, que proíbe a orientação e distribuição de livros às escolas públicas que versem sobre orientação e diversidade sexual para crianças e adolescentes. Em contrapartida, é autor do PL 4500/2012, que garante a liberdade de expressão religiosa sobre temas relativos à sexualidade. $\mathrm{O}$ deputado compõe a Frente Parlamentar Evangélica do Congresso Nacional, a Frente Parlamentar Mista da Família e Apoio à Vida e a Frente Parlamentar para a Liberdade Religiosa do Congresso (Mista).

O Senador Magno Malta (PR) foi autor do PLS 193/2016, que tramita no Senado Federal. Malta é pastor evangélico, ligado à Igreja Batista. O senador também é bastante conhecido por oposição aos direitos da comunidade LGBT. Além disso, Malta é defensor da Redução da Maioridade Penal para 16 anos e foi proponente da PEC nº 90, de 2003, 
que propõe alteração da $\mathrm{CF} / 88$ "para considerar penalmente imputáveis os maiores de treze anos que tenham praticado crimes definidos como hediondos".

O deputado Izalci Lucas (PSDB), proponente do PL 867/2015, faz parte da Frente Parlamentar Evangélica do Congresso Nacional e da Frente Parlamentar Mista Católica Apostólica Romana. Segundo a reportagem de Andrea Dip, da Agência Pública, ${ }^{6}$ Lucas recebeu, em sua última campanha, $\mathrm{R} \$ 270.010,34$ em doações de instituições privadas de ensino e declarou $\mathrm{R} \$ 685.502,23$ em investimentos em escolas da rede de ensino privado no mesmo ano (2014).

O PL 1859/2015 é uma proposição de iniciativa coletiva, que conta com a assinatura de Izalci Lucas e outros 13 deputados, ${ }^{7}$ que também aparecem na rede de sujeitos: Alan Rick (PRB/AC), Antonio Carlos Mendes Thame (PSDB/SP), Antonio Imbassahy (PSDB/ $\mathrm{MG})$, Celso Russomanno (PRB/SP), Eduardo Cury (PSDB/SP), Eros Biondini (PTB/MG), Evandro Gussi (PV/SP), Givaldo Carimbão (PROS/AL), João Campos (PSDB/GO), Leonardo Picciani (PMDB/RJ), Luiz Carlos Hauly (PSDB/PR), Rosangela Gomes (PRB/MG) e Stefano Aguiar (PSB/MG).

Ainda no campo legislativo, ganha destaque a família Bolsonaro. Isso porque o deputado Flávio Bolsonaro foi quem solicitou a Miguel Nagib que formulasse os anteprojetos de lei no ano de 2013, documentos que serviram como base a inúmeras proposições da mesma natureza. Flávio foi o primeiro parlamentar a apresentar Projeto de Lei pela instituição do Programa Escola sem Partido, no Estado do RJ, no ano seguinte. Carlos Bolsonaro também é proponente de um PL na Câmara Municipal da cidade do RJ. Além disso, os deputados da família Bolsonaro são apoiadores manifestos da proposta nos diferentes espaços de debate público.

O grupo Revoltados Online ( $\mathrm{RO}$ ), que disputou a liderança das manifestações pelo impeachment da presidenta Dilma, assume protagonismo em relação ao ESP, na ocasião em que Marcello Reis, fundador do movimento, e o ator Alexandre Frota reuniram-se com o ministro da educação, Mendonça Filho e apresentaram a pauta do ESP para o Ministério da Educação. Fundado em 2010, o grupo RO assume posições conservadoras e à direita, defendendo a intervenção militar e os valores de Deus e da família.

Um sujeito coletivo que se destaca tanto em relação ao legislativo quanto às outras frentes de atuação do ESP é o Movimento Brasil Livre (MBL), que foi uma grande liderança do movimento pró-impeachment de Dilma Rousseff no ano de 2015 e é grande defensor do ESP, tendo aprovado como diretriz no seu primeiro congresso a apresentação do projeto em legislativos estaduais e municipais (LIMA, 2017). Um deputado federal e sete vereadores representantes do MBL foram eleitos em 2016 e são divulgadores do movimento nas redes sociais, através de diferentes ações, como a do vereador da cidade de São Paulo, Fernando Holiday (DEM-SP), que atua fazendo visitas surpresas a escolas municipais para verificar a ocorrência de "doutrinação ideológica". 
Quanto à origem do MBL, Amaral (2016) constatou que ele é nada mais que um nome fantasia da Estudantes pela Liberdade (EPL). O movimento surgiu como uma "marca" para a EPL se promover nas manifestações à época do impeachment, já que a legislação estadunidense impede a atuação política das fundações americanas. A EPL, por sua vez, é a versão local da Students for Liberty (SFL), uma organização estudantil internacional, fundada em 2008, vinculada e financiada pela Atlas Network, uma rede de fundações de direita, sediada nos EUA, à qual são ligados diversos institutos nacionais e internacionais, entre eles o Cato Institute, o Instituto de Estudos Empresariais (IEE), o Instituto Liberal, Instituto Mises Brasil e o Instituto Millenium (IMil).

Cabe destacar que o Fórum da Liberdade, promovido pelo Instituto de Estudos Empresariais (IEE), teve sua $30^{\circ}$ edição este ano em Porto Alegre. Neste espaço, cuja palestra de abertura contou com a participação do prefeito de São Paulo, João Dória (PSDB), estiveram presentes figuras como Diogo Costa, diretor do Instituto de Inovação \& Governança (Indigo), que já trabalhou com pesquisas no Cato Institute, na Atlas Network e no Ibmec; Fábio Ostermann, diretor executivo do Instituto Liberdade, conselheiro fiscal do IEE e cofundador da rede EPL e do MBL; Helio Beltrão, fundador do IMil e do Instituto Mises Brasil; e Luciano Potter, jornalista do grupo RBS; entre outros, o que evidencia a inter-relação entre os diferentes institutos e organizações.

Podemos considerar os partidos políticos como sujeitos coletivos que atuam em relação à pauta do ESP. Um levantamento realizado em maio deste ano, que considerou os âmbitos federal, estadual e municipal (capitais), indica que pelo menos 16 partidos políticos foram proponentes de Projetos de Lei da natureza do ESP, todos vinculados a ideias mais à direita e conservadoras (LIMA, 2017). São campeões em proposições o PSDB e o PSC, ambos com 11 proposições cada, seguidos do PMDB com 7 proposições.

A propósito do levantamento dos sujeitos vinculados ao ESP, é possível identificar a atuação de sujeitos de diferentes setores da sociedade. Ainda que não seja nossa intenção categorizar os sujeitos envolvidos, remetemos a Apple (2003) e à chamada modernização conservadora na educação, que se dá como "resultado do esforço bem sucedido da direita de formar uma aliança de bases amplas", que tem entre os grupos centrais os neoliberais e neoconservadores e que, apesar das contradições internas, podem ter êxito na transformação radical da política e da prática educacional (APPLE, 2003).

\section{Considerações finais}

As reformas em curso no Brasil têm se caracterizado pelo empresariamento e neoconservadorismo, que avançam nesse período histórico através dos sujeitos individuais e coletivos dos processos em curso. De um lado, a privatização da política educacional pelo setor privado mercantil e, de outro, o ataque através da censura do conteúdo da 
educação pública, via bancada religiosa no Congresso e de setores neoconservadores da sociedade, vêm se articulando amplamente com instituições globais, disputando projetos societários por dentro da educação.

Consideramos que há um forte movimento de cerceamento ao fazer docente e controle dos processos pedagógicos nas instituições educativas, seja por meio da venda de materiais didático-pedagógicos que padronizam o fazer e o pensar dos professores ou pela legislação que retira do debate educacional a discussão sobre temas inerentes a uma sociedade democrática, como pluralidade e diversidade. Nesse contexto, entendemos que a democracia é incompatível com privatização e censura, pois pressupõe a participação, a coletivização das decisões, o debate de projetos com a sociedade. Os interlocutores das reformas e dos projetos educacionais que vem sendo apresentados no período pós-golpe, têm sido o privado mercantil e os setores mais reacionários cujo objetivo é dar a direção à educação.

Trata-se de projetos em disputa, e a disputa por projetos societários é parte de uma sociedade democrática. No entanto, os projetos dos quais tratamos nesse artigo buscam impedir o debate e a divergência de ideias e concepções, negando os que sejam ideologicamente opostos aos seus. Por isso, apresentam meios para censurar os professores, estudantes, pesquisadores e entidades que historicamente lutaram pela escola pública e o direito à educação.

Recebido em 29/09/2017 e aprovado em 12/10/2017

\section{Notas}

1 É sócio e co-presidente da Cambuhy Investimentos, conselheiro da TOTVS e membro do Conselho de Administração da Falconi Consultores Associados. Pedro é ainda membro do Conselho Orientador da Fundação Osesp e membro do Conselho Deliberativo do Insper.

2 Malan defendeu as privatizações de empresas estatais federais e estaduais como forma de aumentar a eficiência da economia e reduzir os gastos do governo FHC. Foi presidente do Banco Central no governo Itamar Franco e ministro da Fazenda de FHC.

3 A Fundação Lemann é presidida por Jorge Lemann, bilionário brasileiro que está em primeiro lugar na lista da Revista Forbes como o homem mais rico do Brasil. https://www.pragmatismopolitico.com. br/2014/05/15-familias-mais-ricas-brasil.html

4 Exerceu esse mesmo cargo, em 2002, durante o governo FHC. Antes disso, ela foi presidente do Instituto Nacional de Estudos e Pesquisas Educacionais (Inep), de 1995 e 2001. Nesse período, organizou e implantou o Exame Nacional de Cursos, conhecido como Provão, o Exame Nacional do Ensino Médio (Enem), o Sistema Nacional de Avaliação da Educação Básica (Saeb) e o Sistema Nacional de Informação Educacional, que contempla os censos escolares e a produção de estatísticas educacionais. Também foi secretária de Estado de Educação de São Paulo, de 2007 a 2009. Nas últimas eleições presidenciais, foi responsável pela área de Educação do programa de governo do candidato Aécio Neves (PSDB).Está ligada a instituições do Todos pela Educação. 
5 Atuou entre 1996 e 2002, no governo FHC (no Inep), tendo participado da criação e implementação do Enem e na SE do estado de São Paulo onde foi responsável pelas avaliações e bonificação aos professores.

6 Disponível em http://apublica.org/2016/08/escola-sem-partido-caca-bruxas-nas-salas-de-aula/. Acesso em 22 jun. 2017.

7 Em princípio, eram 16 assinaturas, mas Diego Garcia (PHS) e Flavinho (PSB) retiraram suas assinaturas do projeto, o primeiro ainda em junho de 2015 e o segundo em outubro de 2016.

\section{Referências}

AMARAL, Marina. Jabuti não sobre em árvore: como o MBL se tornou líder das manifestações pelo impeachment. In: CLETO, Murilo; DORIA, Kim; JINKINGS, Ivana (Org.). Por que gritamos golpe? Para entender o impeachment e a crise política no Brasil. São Paulo: Boitempo, 2016, p. 49-54.

APPLE, Michael. Educando à direita: mercados, padrões, Deus e desigualdade. São Paulo: Cortez/ Instituto Paulo Freire, 2003.

BALL. Stephen. Educação Global S.A. Novas redes políticas e o imaginário neoliberal. Ponta Grossa, UEPG, 2014.

BRAIT, Daniele. Os protagonistas do Escola sem Partido. In: A ideologia do movimento Escola sem Partido: 20 autores desmontam o discurso. Ação Educativa Assessoria, Pesquisa e Informação. São Paulo: Ação Educativa, 2016. p.161-165.

FAGNANI. Eduardo. O fim do breve ciclo da cidadania social no Brasil (1988-2015). Texto para Discussão. Unicamp. IE, Campinas, n. 308, jun. 2017.

GONÇALVES. Suzane da Rocha Vieira. Interesses mercadológicos e o "novo" ensino médio. Revista Retratos da Escola, Brasília, v. 11, n. 20, p. 131-145, jan./jun. 2017.

HARVEY, David. O Neoliberalismo: história e implicações. São Paulo: Loyola, 2008.

LIMA, Paula Valim de. Escola sem sentido: implicações do Escola sem Partido para a democratização da educação pública. UFRGS. Trabalho de Conclusão de Curso de Graduação. 2017

MACEDO, Elizabeth. As demandas conservadoras do movimento Escola sem Partido e a Base Nacional Curricular Comum. Educ. Soc, v. 38, n.139, 507-524, 2017.

MÉSZÁROS, István. A educação para além do capital. São Paulo: Boitempo Editorial, 2006.

MIGUEL, Luis Felipe. Da “doutrinação marxista" à "ideologia de gênero" - Escola sem Partido e as leis da mordaça no parlamento brasileiro. Revista Direito e Práxis, V. 07, n.15, p. 590-621, 2016.

PERONI, Vera. Política educacional e papel do Estado no Brasil dos anos 90. São Paulo: Xamã, 2003.

Mudanças na configuração do Estado e sua influência na política educacional. In: PERONI, Vera; BAZZO, Vera Lúcia; PEGORARO Ludimar (Org.). Dilemas da educação brasileira em tempos de globalização neoliberal: entre o público e o privado. Porto Alegre: Editora da UFRGS, 2006. p. 11-24.

Redefinições no Papel do Estado e o Público Não-Estatal: implicações para a democratização de direitos materializados em políticas sociais. In: MACIEL, Ana Lúcia Suárez; BORDIN, Erica Bomfim (Org.). A Face Privada na Gestão das Políticas Públicas. Porto Alegre: FIJO, 2014. P. 182-209. 
. Implicações da relação público-privada para a democratização da educação no Brasil. In: PERONI, Vera Maria Vidal (Org.). Diálogos sobre as redefinições do papel do Estado e sobre as fronteiras entre o público e o privado. São Leopoldo: Oikos, 2015. p. 15-34.

As Implicações da relação público-privada para a democratização da educação no Brasil. Tese (promoção a Professor Titular da Carreira do Magistério Superior), UFRGS. 2016.

PERONI V. M; CAETANO, M. R. O público e o privado na educação Projetos em disputa? Revista Retratos da Escola, Brasília, v. 9, n. 17, p. 337-352, jul./dez. 2015.

THOMPSON, E. P. A miséria da teoria ou um planetário de erros. Rio de Janeiro: Zahar, 1981.

UNIBANCO. Instituto. Parceiros. Disponível em http://www.institutounibanco.org.br/parceiros/. Acesso em 10 set.2017.

Instituto. Seminário Currículo. Materiais. Disponível em http://www.seminariocurriculo.org. br/site/2017/\#inicio. Acesso em 2 set. 2017. 